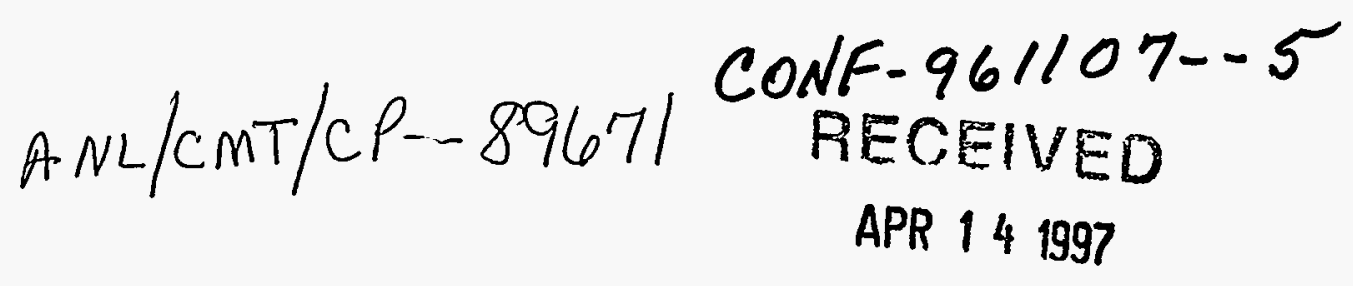
X-RAY ABSORPTION AND ELECTROCHEMICAL STUDIES
DIRECT METHANOL FUEL CELL CATALYSTS

D. J. Zurawski, A. J. Aldykiewicz, Jr., S. F. Baxter, and M. Krumpelt Electrochemical Technology Program

Argonne National Laboratory 9700 South Cass Avenue

Argonne, II 60439
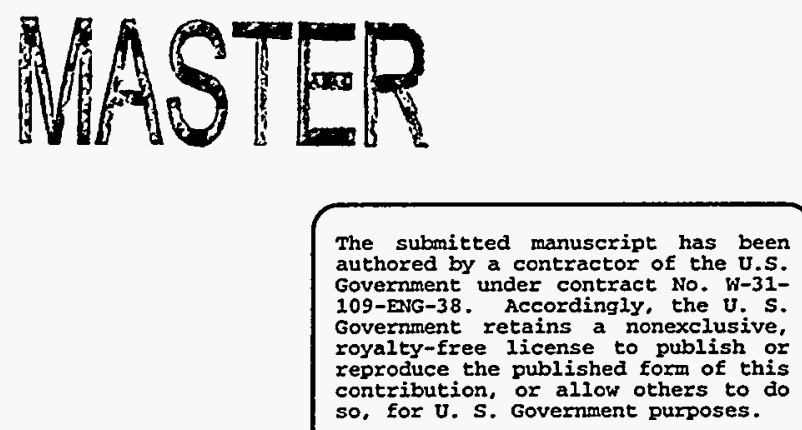

Poster to be presented at the 1996 Fuel Cell Seminar to be held on November 17-20, 1996, Kissimmee, Florida.

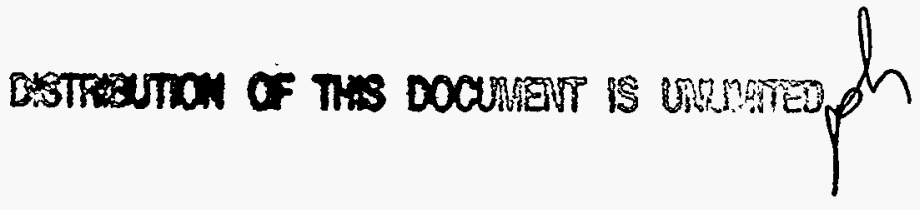




\section{DISCLAIMER}

This report was prepared as an account of work sponsored by an agency of the United States Government. Neither the United States Government nor any agency thereof, nor any of their employees, make any warranty, express or implied, or assumes any legal liability or responsibility for the accuracy, completeness, or usefulness of any information, apparatus, product, or process disclosed, or represents that its use would not infringe privately owned rights. Reference herein to any specific commercial product, process, or service by trade name, trademark, manufacturer, or otherwise does not necessarily constitute or imply its endorsement, recommendation, or favoring by the United States Government or any agency thereof. The views and opinions of authors expressed herein do not necessarily state or reflect those of the United States Government or any agency thereof. 


\title{
X-RAY ABSORPTION AND ELECTROCHEMICAL STUDIES OF DIRECT METHANOL FUEL CELL CATALYSTS
}

\author{
Deborah J. Zurawski, Antonio J. Aldykiewicz, Jr., Shannon F. Baxter, and Michael Krumpelt \\ Electrochemical Technology Program \\ Argonne National Laboratory \\ 9700 South Cass Avenue \\ Argonne, Illinois 60439 .
}

\section{Introduction}

In order for polymer electrolyte fuel cells to operate directly on methanol instead of hydrogen, a distinct advantage for portable applications, methanol oxidation must be catalyzed effectively in the acidic environment of the cell. Platinum-ruthenium and platinum-ruthenium oxide are generally considered to be the most active catalysts for this purpose. The presence of ruthenium significantly enhances the activity of platinum in these catalysts, for reasons not yet fully understood. We are using $\mathrm{X}$-ray absorption spectroscopy (XAS) and electrochemical techniques to evaluate the mechanisms proposed to account for this enhancement in order to further improve the catalyst's activity.

We are considering three enhancement mechanisms. An intermediate in the oxidation of methanol on platinum is carbon monoxide and its oxidation is the rate-determining step in the overall oxidation mechanism [1]. It has been proposed that ruthenium facilitates the removal of carbon monoxide from the platinum surface [2]. First, it has been proposed that ruthenium decreases the strength of the platinum-carbon monoxide bond. Carbon monoxide bonds to the catalyst by interacting with the $\mathrm{d}$-band of platinum [3], therefore a change in the d-band occupancy of platinum as a result of alloying may influence the bond strength of carbon monoxide. Another proposed enhancement mechanism involves lowering of the potential for the formation of the CO-oxidizing species [2]. Finally, the binary catalysts may have a structure which is more conducive to the methanol dehydrogenation and

carbon monoxide reactions [4]. Based on these three proposed enhancement mechanisms, a goal of this study is to correlate catalyst electronic properties, structure, and oxidation state with the performance of proton-exchange membrane (Nafion) direct methanol fuel cells.

\section{Experimental}

We have used XAS to determine the effect of carbon support and ruthenium concentration on the $\mathrm{d}$-band occupancy, structure, and oxidation state of platinum-ruthenium. We also determined the effect of electrode fabrication [5] (mixing with solubilized Nafion and hot-pressing to a Nafion membrane) on the platinum-ruthenium oxide and platinum-ruthenium catalysts. The activity of the platinum-ruthenium catalysts for methanol oxidation was determined using steady-state galvanostatic measurements on the catalysts incorporated in full membrane-electrode assemblies (MEAs).

Unsupported and carbon-supported (Vulcan XC-72R, Cabot) platinum and platinum-ruthenium alloy catalysts were synthesized by reduction from an aqueous solution of the metal chlorides. The resulting catalyst particles were dried, and heat-treated at $250^{\circ} \mathrm{C}$ in a reducing atmosphere. The compositions tested range from 0 to $42 \mathrm{~mol} \%$ ruthenium. X-ray diffraction (XRD) analysis verified that the platinum and ruthenium are alloyed. An unsupported metal oxide catalyst of nominal composition $\mathrm{PtRuO}_{x}$ was provided by an outside vendor. XRD analysis showed this material to consist of a mixture of platinum and ruthenium oxide.

XAS measurements were made of the catalyst powders supported on X-ray transparent tape, supported in Nafion (EW=1100, DuPont), and in MEAs. These experiments were performed at beamlines $\mathrm{X}-19 \mathrm{~A}$ and X-23A2 at the National Synchrotron Light Source at Brookhaven National Laboratory. 


\section{ZURAWSKI ET AL}

$-2-$

The scanned $\mathrm{X}$-ray energy ranges covered the $\mathrm{Pt}_{3}$ and $\mathrm{L}_{2}$ edges and the Ru K edge (X-23A2 only). Absorption measurements of a platinum foil and ruthenium black pellet were made simultaneously with those of the catalyst samples to calibrate the monochromator. The coordination numbers and $\mathrm{Pt}-\mathrm{Pt}$ bond distances were calculated from fits to the EXAFS portion of the $\mathrm{L}_{3}$ absorption edge following published procedures [6,7]. The $d$-band occupancy of platinum was determined from the height of the $\mathrm{L}_{3}$ absorption edge [8]. Oxidation states of ruthenium and platinum in the catalysts were determined by comparing the XAS spectra of the catalysts with those obtained for platinum and ruthenium compounds with known oxidation states.

The electrochemical activity of the catalysts for the oxidation of methanol was evaluated in full MEAs fabricated by the ink technique [5]. Catalyst loadings were approximately $4 \mathrm{mgPt} / \mathrm{cm}^{2} / \mathrm{electrode}$. The MEA test apparatus consists of two graphite blocks with machined reactant flow channels and carbon cloth (E-Tek) or carbon paper (Spectracorp) flow fields. The anode and cathode were supplied with deaerated $2 \underline{\mathrm{M}}$ methanol and hydrogen,respectively, both at $0 \mathrm{psig}$. Using this configuration, the cathode acted as both the counter and reference electrodes and allowed measurement of the anode overpotential. The cell temperature was maintained at $90^{\circ} \mathrm{C}$.

\section{Results and Discussion}

The $\mathrm{Pt}_{3} \mathrm{X}$-ray absorption promotes electrons to $5 \mathrm{~d}$ orbitals. The height of the $\mathrm{L}_{3}$ absorption edge is a measure of the probability of this transition and therefore is proportional to the number of vacancies in the $5 \mathrm{~d}$ orbitals. The normalized height of the $\mathrm{Pt}_{3}$ absorption edge is compared in Fig. 1 for the supported and unsupported platinum catalyst particles and in Fig. 2 for catalyst particles with ruthenium compositions ranging from 0 to $42 \mathrm{~mol} \%$. As seen from these figures, both the carbon support and the presence of ruthenium increase the number of platinum d-band vacancies (i.e., withdraw electrons). The electron-withdrawing effect of ruthenium observed here is in agreement with the results of McBreen and Mukerjee [9].

The activity for methanol oxidation was found to increase with addition of ruthenium to the catalyst. This increase in activity is illustrated in Fig. 3 as an increase in the total methanol oxidation current (normalized to the total weight of platinum in the anode) at a given overpotential. The $58 \mathrm{~mol} \%$ platinum $/ 42 \mathrm{~mol} \%$ ruthenium alloy was found to be the most active for methanol oxidation of the four catalysts tested.

The alloy catalysts were found to consist of platinum and ruthenium, whereas the nominal $\mathrm{PtRuO}_{\mathrm{x}}$ was a mixture of platinum oxide and ruthenium oxide. No change was observed in the oxidation state of the alloys when they were supported in Nafion. The electrode fabrication procedure reduced the oxidation state of platinum in the $\mathrm{PtRuO}_{x}$ catalyst, but not the oxidation state of ruthenium.

Our preliminary results indicate that ruthenium does effect the d-band occupancy of platinum, which in turn may effect the kinetics of the methanol oxidation reaction on this metal by altering the strength of the platinum-carbon monoxide bond. Futher research is needed to clarify the effect of ruthenium concentration on platinum's d-band occupancy, to establish the optimum d-band occupancy for the methanol oxidation reaction, and also to determine the oxidation states of platinum and ruthenium during methanol oxidation.

\section{Acknowledgment}

The authors gratefully acknowledge the collaboration of Professors Carlo Segre, Grant Bunker, and Eugene Smotkin of the Illinois Institute of Technology. This research was sponsored by the 
U.S. Army Research Office, Research Triangle Park, NC, through the Fuel Cell/Battery Research Hub at the Illinois Institute of Technology. This research was conducted at Argonne National Laboratory which is operated by the University of Chicago for the U.S. Department of Energy under Contract No. W-31-109-Eng-38. X-Ray experiments were performed at the National Synchrotron Light Source at Brookhaven National Laboratory, Upton, NY.

\section{References}

1. B. Beden, C. Lamy, A. Bewick, K. Kunimatsu, J. Electroanal. Chem., Vol. 121, pp. 343-347, 1981.

2. R. Parsons and T. VanderNoot, J. Electroanal. Chem., Vol. 257, pp. 9-45, 1988.

3. G. Blyholder, J. Phys. Chem., Vol. 68, p. 2772, 1964.

4. H. Gasteiger, N. Markovic, P.N. Ross, Jr., and E. Cairns, J. Phys. Chem., Vol. 97, pp. 12020- . 12029, 1993.

5. M.S. Wilson and S. Gottesfeld, J. Appl. Electrochem., Vol. 22, pp. 1-7, 1992.

6. J.J. Rehr, R.C. Albers, and S.I. Zabinsky, Phys. Rev. Lett., Vol. 69, p. 3397, 1992.

7. J.J. Rehr, Jpn. J. Appl. Phys., Vol. 32, p. 8, 1993.

8. A.N. Mansour, J.W. Cook, Jr., and D.E.Sayers, J. Phys. Chem., Vol. 88, pp. 2330-2334, 1984.

9. J. McBreen and S. Mukerjee, J. Electrochem. Soc., Vol. 142, pp. 3399-3404, 1995.

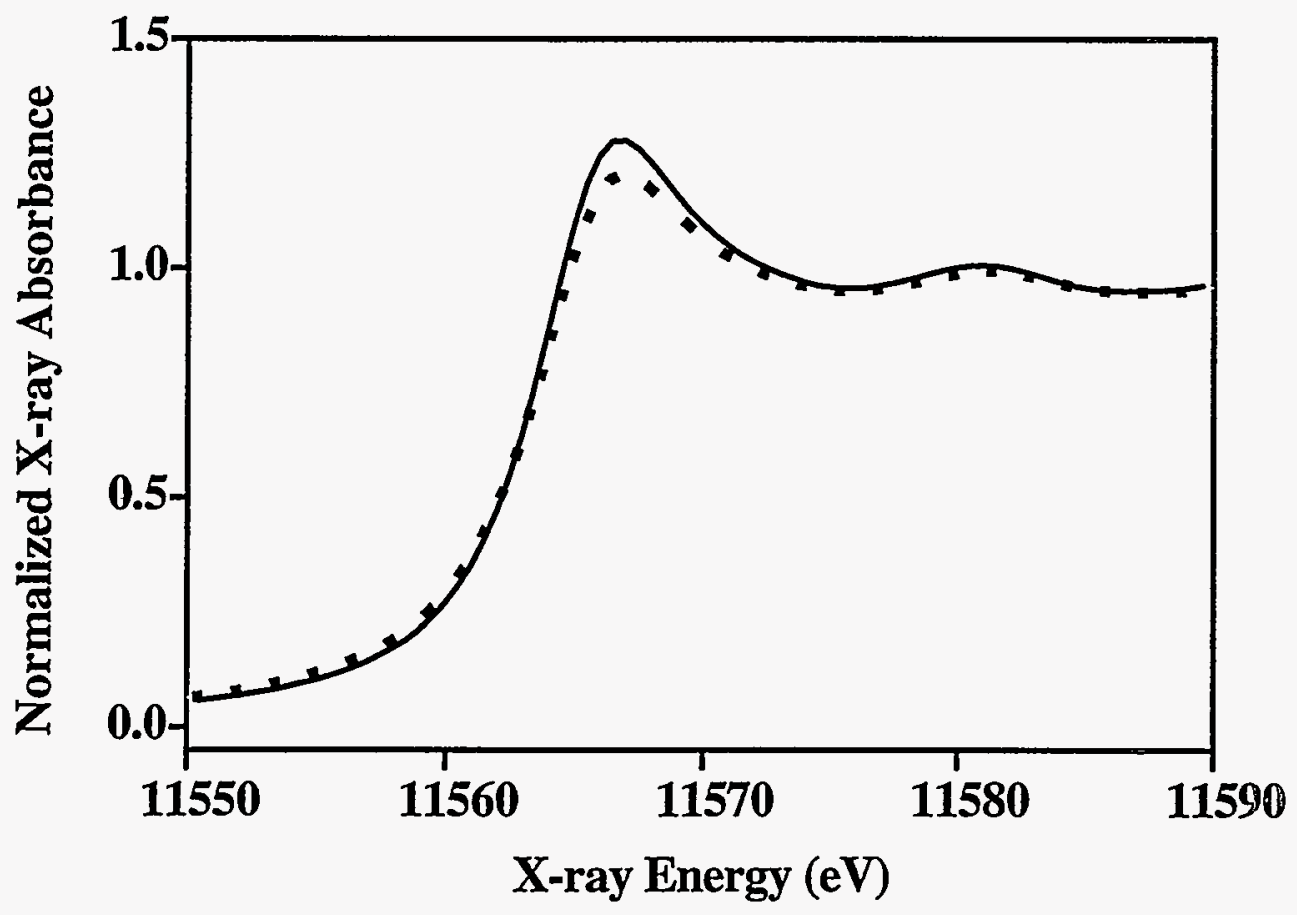

Figure 1. $\mathrm{Pt} \mathrm{L}_{3} \mathrm{X}$-ray absorption for 50 mol\% PtRu catalyst, unsupported (dashed line) and supported on carbon (solid line). 


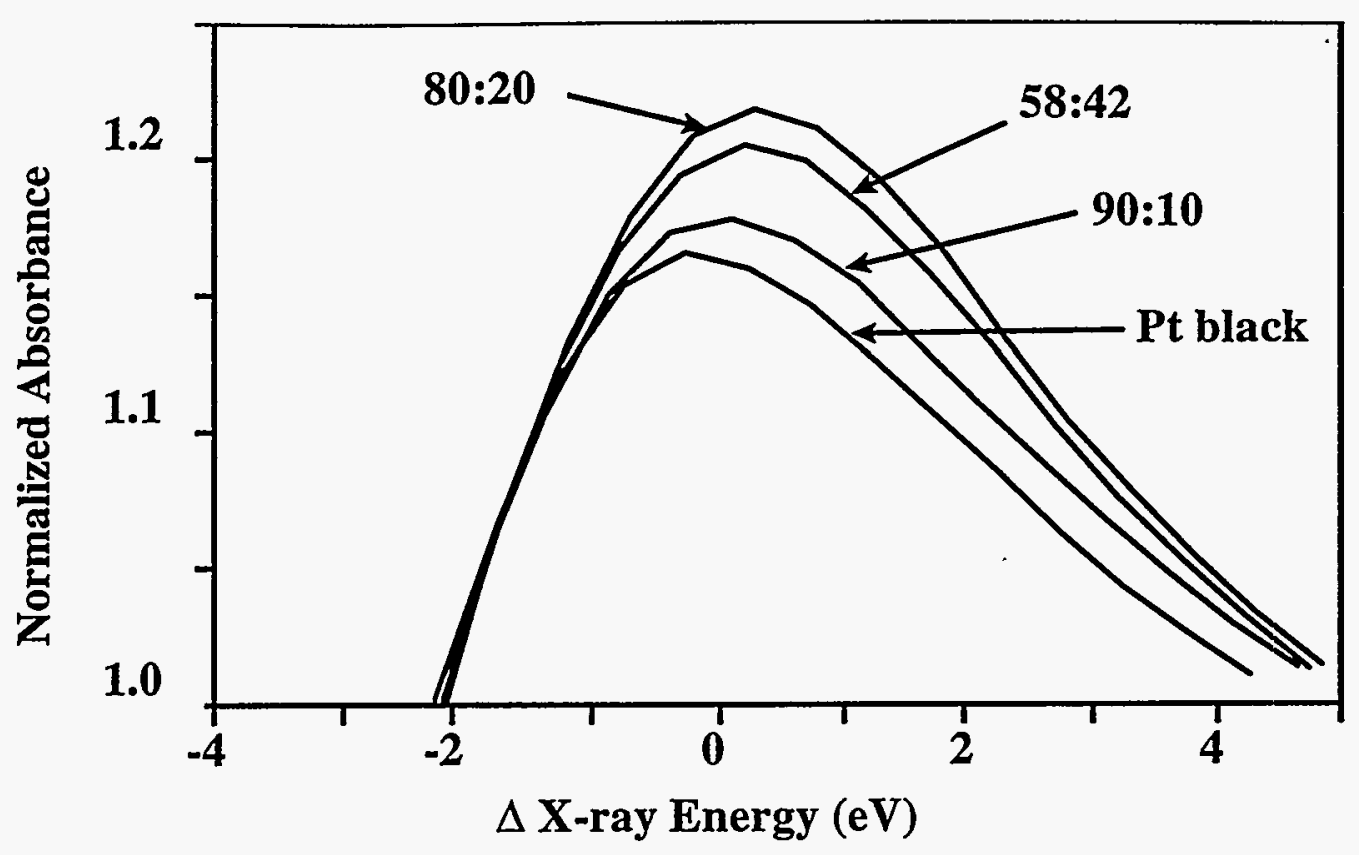

Figure 2. $P t \mathrm{~L}_{3} \mathrm{X}$-ray absorption for unsupported $\mathrm{Pt}$ and $\mathrm{PtRu}$ catalysts. Indicated ratios are mole \% $\mathrm{Pt}: \mathrm{mol} \% \mathrm{Ru}$ for the alloy catalysts.

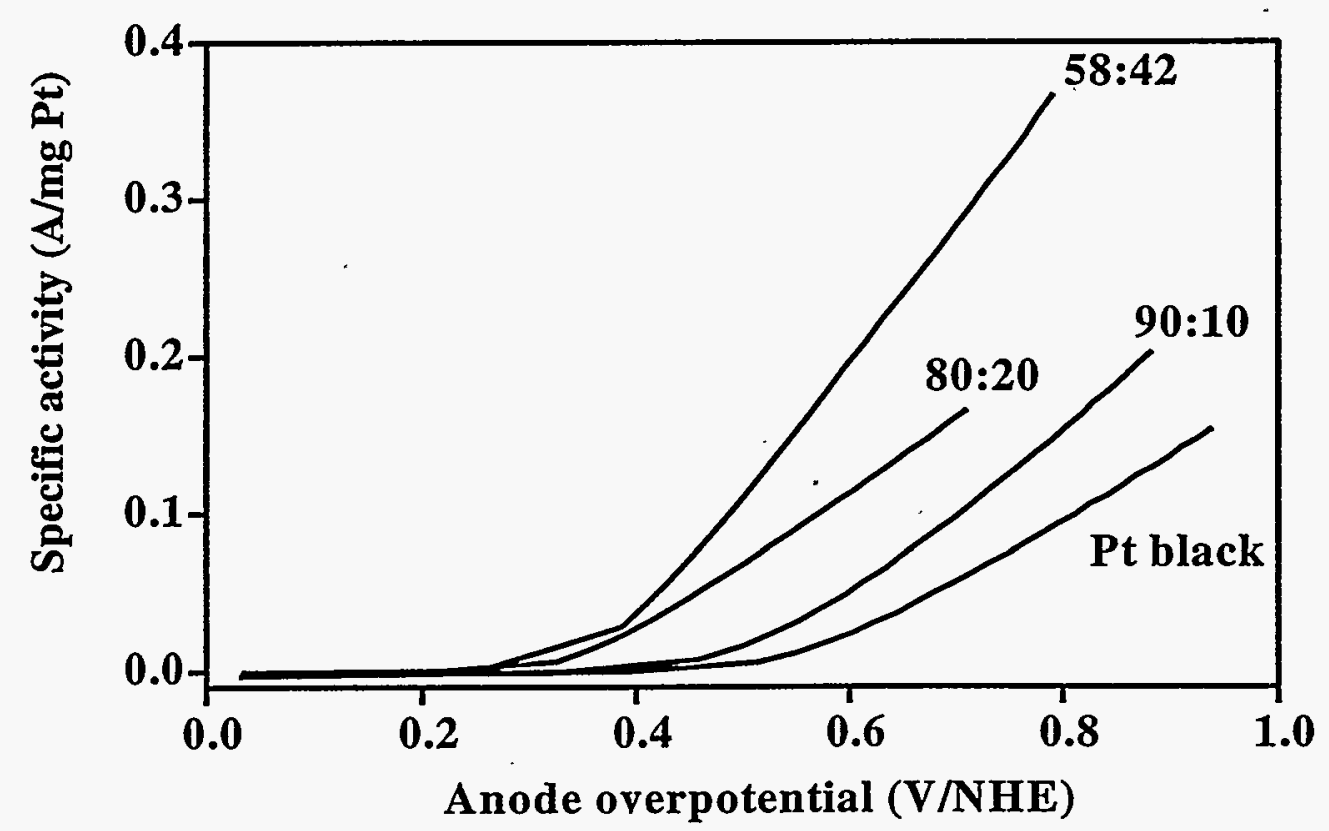

Figure 3. Specific activity for methanol oxidation of unsupported Pt and PtRu catalysts. Indicated ratios are $\mathrm{mol} \% \mathrm{Pt}: \mathrm{mol} \% \mathrm{Ru}$ in the alloy catalysts. 